\title{
Analyses of Hypernuclei Produced Via Fission and Evaporation
}

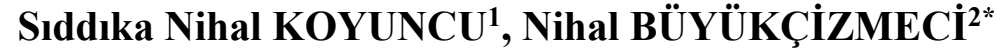 \\ *Corresponding Author: nihal@selcuk.edu.tr \\ ${ }^{1}$ Selcuk University, Faculty of Science, Department of Physics, 42130, KONYA \\ Orcid No: 0000-0002-6452-3332 / nihalkilboz.koyuncu@gmail.com \\ ${ }^{2}$ Selcuk University, Faculty of Science, Department of Physics, 42130, KONYA \\ Orcid No: 0000-0002-6030-9574 / nihal@selcuk.edu.tr
}

\begin{abstract}
In heavy-ion reactions, nuclei and hypernuclei yields can be emitted from target/projectile rediuals in peripheral collisions. The evaporation and fission yields are investigated at $0.25-2.5 \mathrm{MeV} / \mathrm{nucleon}$ excitation energy intervals for source nuclei ${ }^{235} \mathrm{U},{ }_{\Lambda}^{235} \mathrm{U},{ }_{\Lambda \Lambda}^{235} \mathrm{U},{ }_{3 \Lambda}^{235} \mathrm{U},{ }_{4 \Lambda}^{235} \mathrm{U},{ }^{168} \mathrm{Ho},{ }_{\Lambda}^{168} \mathrm{Ho},{ }_{\Lambda \Lambda}^{168} \mathrm{Ho},{ }_{3 \Lambda}^{168} \mathrm{Ho}$, and ${ }_{4 \Lambda}^{168} \mathrm{Ho}$. We have reproduced mass distributions via computer codes by using hyper-SMM model which is based on the statistical multifragmentation model for hypernuclei. Our results can be used for the analyses of the future experiments at FAIR(GSI) and NICA(Dubna).
\end{abstract}

Keywords: Evaporation, Fission, Hypernuclei, Statistical Multifragmentation Model

\section{Fisyon ve Buharlaşma ile Üretilen Hiperçekirdeklerin Analizi}

Öz: Ağır iyon reaksiyonlarında çekirdekler ve hiperçekirdekler yanal çarpışmalarda hedef $/$ mermi çekirdek artıklarından saçlabilir. ${ }^{235} \mathrm{U},{ }_{\Lambda}^{235} \mathrm{U},{ }_{\Lambda \Lambda}^{235} \mathrm{U},{ }_{3 \Lambda}^{235} \mathrm{U},{ }_{4 \Lambda}^{235} \mathrm{U},{ }^{168} \mathrm{Ho},{ }_{\Lambda}^{168} \mathrm{Ho},{ }_{\Lambda \Lambda}^{168} \mathrm{Ho},{ }_{3 \Lambda}^{168} \mathrm{Ho}$ ve ${ }_{4 \Lambda}^{168} \mathrm{Ho}$ kaynak çekirdekleri için $0.25-2.5 \mathrm{MeV} /$ nükleon uyarma enerji aralıklarında buharlaşma ve fisyon ürünleri araştırılmıştır. Hiperçekirdekler için istatistiksel çok katlı parçalanma modeli temelinde hiper-SMM modelini kullanarak bilgisayar kodlarıyla kütle dağılımlarını elde ettik. Sonuçlarımız FAIR (GSI) ve NICA (Dubna)'daki gelecek deneylerin analizlerinde kullanılabilecektir.

Anahtar Kelimeler: Buharlaşma, Fisyon, Hiperçekirdekler, Istatistiksel Çok Katlı Parçalanma Modeli

\section{Introduction}

During the last 20 years, the investigations are increased to understand the properties of hypernuclei as theoretically and experimentally. One of the main purposes in experiments is to obtain and analyze the hypernuclei to understand phenomenology in nuclear physics. The hyperons $(\lambda, \Sigma, \Omega, \Xi)$ obtained in highenergy reactions gives an opportunity to extend traditional nuclear studies and widens horizons for studying particle physics and nuclear astrophysics (see, e.g., Hashimoto et al., 2006; Schaffner et al., 1993; Gal et al., 2012; Buyukcizmeci et al., 2013; 2018; 2019; 2020; and references therein). So far, a lot of experiments were devoted to study associated with fission, evaporation and multifragmentation processes, particular, ALADIN (Kreutz et al., 1993; Botvina et al., 1987; 1995; Xi et al., 1997; Ogul et al., 2011), EOS (Scharenberg et al., 2001), ISIS (Viola et al., 2001; Pienkowski et al., 2002), FASA 
(Karnaukhov et al., 2008) and other experimental collaborations have provided very high-quality data. There are many dynamical and statistical models were developed for the theoretical purposes. Especially, the hybrid approaches take into account the descriptions of the nonequilibrium dynamical reaction stage, and the following decay of the equilibrated nuclear sources as properly depending on limitited conditions. Additionally, the statistical models were very successful (SMM (Bondorf et al., 1995) and MMMC (Li et al., 1993)) for the description of the fragment production, so it is started to generalization of model for production of hypernuclei by Botvina and Pochodzalla in 2007 (Botvina and Pochodzalla, 2007).

\section{Material and Methods}

In this study, we have used the statistical multifragmentation model modified for single and multi-Lambda nuclei and called as hyper-SMM (Botvina and Pochodzalla, 2007; Buyukcizmeci et al., 2013; 2018; 2019; 2020; Botvina et al., 2016).

In the Grand Canonical approach, average yields of individual fragments $Y_{\mathrm{A}, \mathrm{Z}, \mathrm{H}}$ is given by as follows:

$\mathrm{g}_{\mathrm{A}, \mathrm{Z}, \mathrm{H}} \cdot V_{f} \frac{A^{3 / 2}}{\lambda_{T}^{3}} \cdot \exp \left[-\frac{1}{T}\left(-\left(F_{\mathrm{A}, \mathrm{Z}, \mathrm{H}}-\mu_{\mathrm{A}, \mathrm{Z}, \mathrm{H}}\right)\right]\right.$, and where $\mu_{\mathrm{A}, \mathrm{Z}, \mathrm{H}}=A \mu+Z v+H \xi$, with the mass $A$, charge $Z$, and the $\Lambda$-hyperon number $\mathrm{H} . \mathrm{T}$ is the temperature, $F_{\mathrm{A}, \mathrm{Z}, \mathrm{H}}$ is the internal free energies of these fragments, $V_{f}$ is the free volume available for the translation motion of the fragments, $\mathrm{g}_{\mathrm{A}, \mathrm{Z}, \mathrm{H}}$ is the spin degeneracy factor of species with A, $\mathrm{Z}$, and $\mathrm{H}, \lambda_{T}=\left(2 \pi \hbar^{2} / m_{N} T\right)^{1 / 2}$ is the baryon thermal wavelength, $m_{N}$ is the average baryon mass. The chemical potentials $\mu, v$, and $\xi$ are responsible for the mass number, charge, and strangeness conservation in the system, and they can be numerically found from the corresponding conservation laws accounting for the total baryon number $A_{0}$, the total charge $Z_{0}$, and the total hyperon number $H_{0}$ in the system. In this model the statistical ensemble includes all break-up channels include baryons and excited fragments. The primary fragments are formed in the freeze-out volume $V . V=V_{0}+V_{f}$, where $V_{0}=A_{0} / \rho_{0}$ $\left(\rho_{0} \cong 0.15 \mathrm{fm}^{-3}\right.$ is the normal nuclear density), and $V_{f}=K \cdot V_{0}$ is the free volume, with $K \cong 2$, as similar in experiments. The binding energy $E_{A}^{b h}$ of one hyperon at the temperature $T$ inside a hypernucleus with $(\mathrm{A}, \mathrm{Z}, \mathrm{H})$ is defined as $E_{A}^{b h}=F_{\mathrm{A}, \mathrm{Z}, \mathrm{H}}-$ $F_{\mathrm{A}-1, \mathrm{Z}, \mathrm{H}-1}$. The details of hyper-SMM model including the description of evaporation, fission and multifragmentation processes can be found in our previous publications (see, e.g. Botvina and Pochodzalla, 2007, Buyukcizmeci et al., 
2013; 2018; 2019; 2020; Botvina et al., 2016).

In this work, we consider the generalization of the evaporation developed in Refs. (Bondorf et al., 1995; Botvina et al., 1987; Buyukcizmeci et al., 2005; Imal et al. 2015) and extended version for hypermatter (Botvina et al., 2016). One of the deexcitation of heavy nuclei $(A \geq 100)$ is the fission of nuclei. This fission races with particle emission, and it is simulated with the Monte Carlo method at each step of the evaporation-fission cascade. In hyper-SMM, according to the Bohr-Wheeler statistical approach assumption, the partial width for the normal compound nucleus fission is proportional to the level density at the saddlepoint. The height of the fission barrier is determined by the Myers-Swiatecki prescription. We have used the results of the extensive analysis of nuclear fissility and branching ratios as in Ref. (Bondorf et al., 1995). Similar to the evaporation case, we consider hypernuclei with a small number of absorbed hyperons, the level density properties and the fission mechanism will not change considerably according to normal nuclei. The modification should concern the terms depending on the mass formulas because heavy hypernuclei are more strongly bound. For this reason, the fission barrier for hypernuclei will be higher than that normal nuclei.

\section{Results and Discussion}

Fig. 1 illustrates the mass distributions of ${ }_{4 \Lambda}^{235} \mathrm{U}$ source after decay at excitation energies $E^{*}=0.25,0.5,0.75$ and 1 $\mathrm{MeV} /$ nucleon. These low excitation energies are selected to see how the mass distributions of produced fragments depending on the decay processes such as evaporation and fission. Since it is very instructive to understand evolution of the mass distributions, we also show total nuclei, normal nuclei and hypernuclei distributions separately in the panels. As can be seen clearly, while the normal nuclei distributions have much more light nuclei on the left hand side peaks (green symbols), the hypernuclei distributions shift to the neutron rich side (black symbols) as expected. Since hypernuclei system has at least one $\Lambda$ up to four, the binding energy will be higher and more stable and neutron rich hypernuclei will appear in the system after decay even if probability of existence of them is lower than normal nuclei. One can see that at low excitations (1 MeV per nucleon) we have standard evaporation and fission. In the topleft panel of Fig. 1, it is clearly seen triple peak of asymmetric fission yields at excitation energy $0.25 \mathrm{MeV} /$ nucleon. The symmetric fission yields appear symmetric distribution (Gaussian type) at excitation energies $0.5,0.75$ and $1 \mathrm{MeV} /$ nucleon. In the regions for $(A \geq 100)$ heavy evaporated residue peak appear with lower probability. 
The evaporation channels will race with fission channels with increasing excitation energy. The size of evaporated heavy residues decreases with increasing energy and number of light particles and neutron numbers increase as expected. These findings are consistent with fission and evaporation processes which was investigated in Refs. (Eren et al., 2007; 2013) for normal nuclei and in Ref. (Botvina et al., 2016) for hypernuclei.

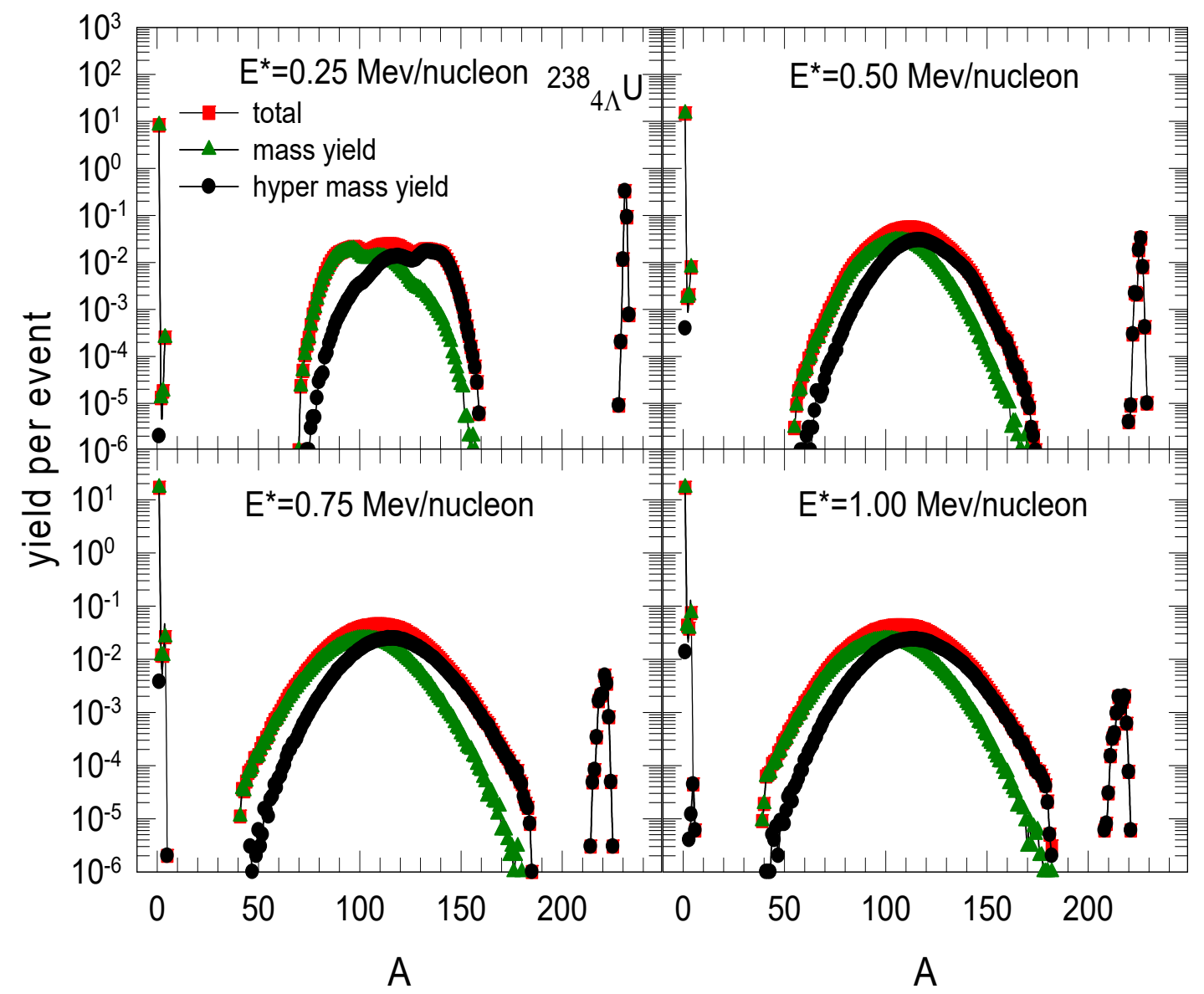

Figure 1. SMM predictions of yields of nuclei and hypernuclei per event versus their mass number, after disintegration of excited systems containing four $\Lambda$ hyperons. Initial mass number $A_{0}=235$, charge number $\mathrm{Z}_{0}=92$, hyperon number $\mathrm{H}_{0}=4$, and excitation energies $\mathrm{E}^{*}=0.25,0.5,0.75$ and $1 \mathrm{MeV} /$ nucleon of the system are shown in the panels. Total yields, normal nuclei and hypernuclei yield are shown as red, green and black symbols, respectively. 


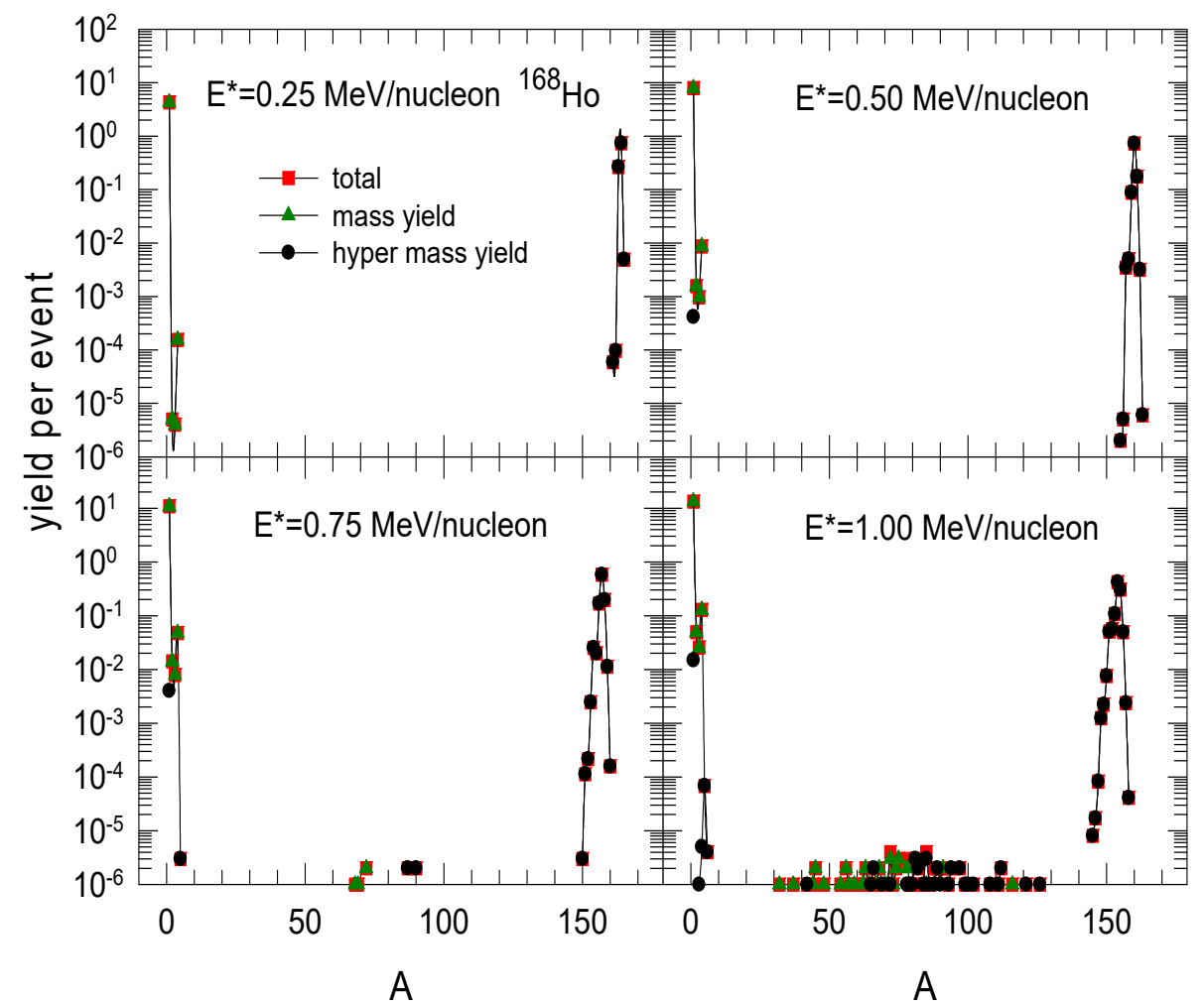

Figure 2. The same as Fig. 1 , but for $A_{0}=168, Z_{0}=67$ and $H_{0}=4$ source nucleus.

initial nuclei. To increase the visibility, each data from bottom to top was increased by 20 percent.

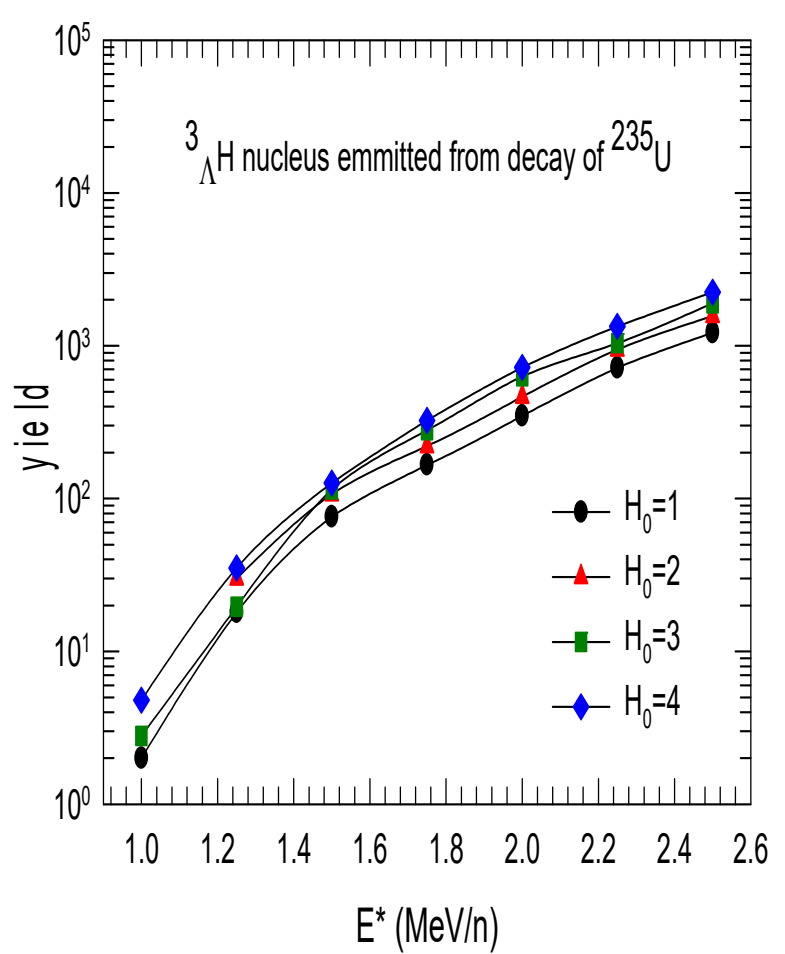

Figure 3. Relative yields of ${ }_{\Lambda}^{3} \mathrm{H}$ after decay of excited initial hypernuclei $A_{0}=235, Z_{0}=92, \quad H_{0}=$ $1,2,3$ and 4 , as function of excitation energy of

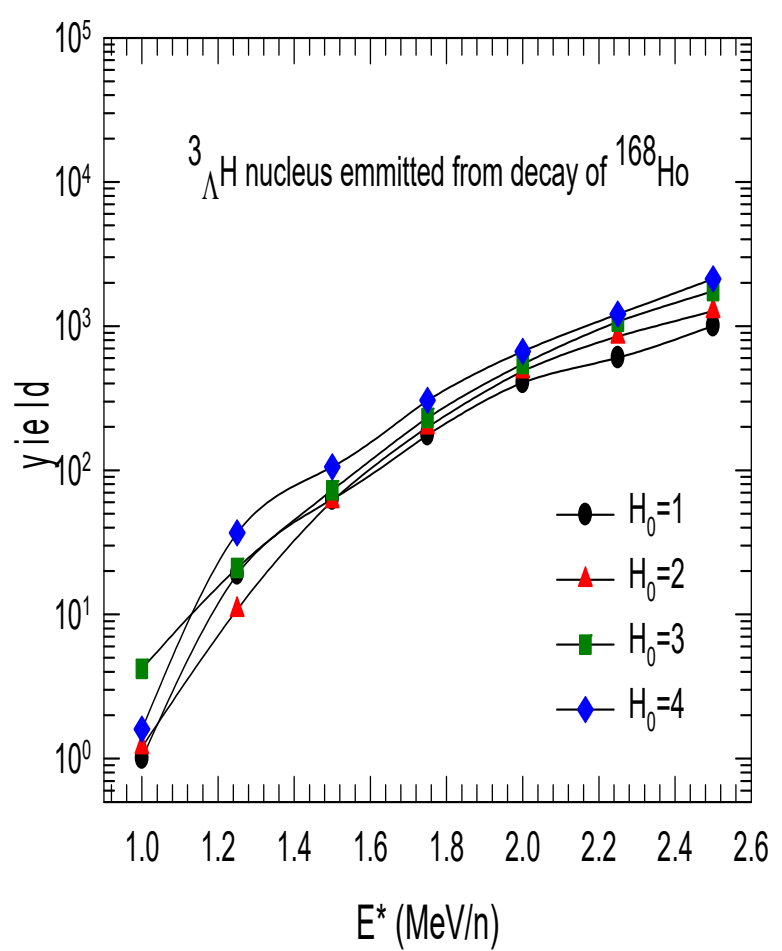

Figure 4. The same as Fig. 3 , but for $\mathrm{A}_{0}=168, \mathrm{Z}_{0}=$ 67. 


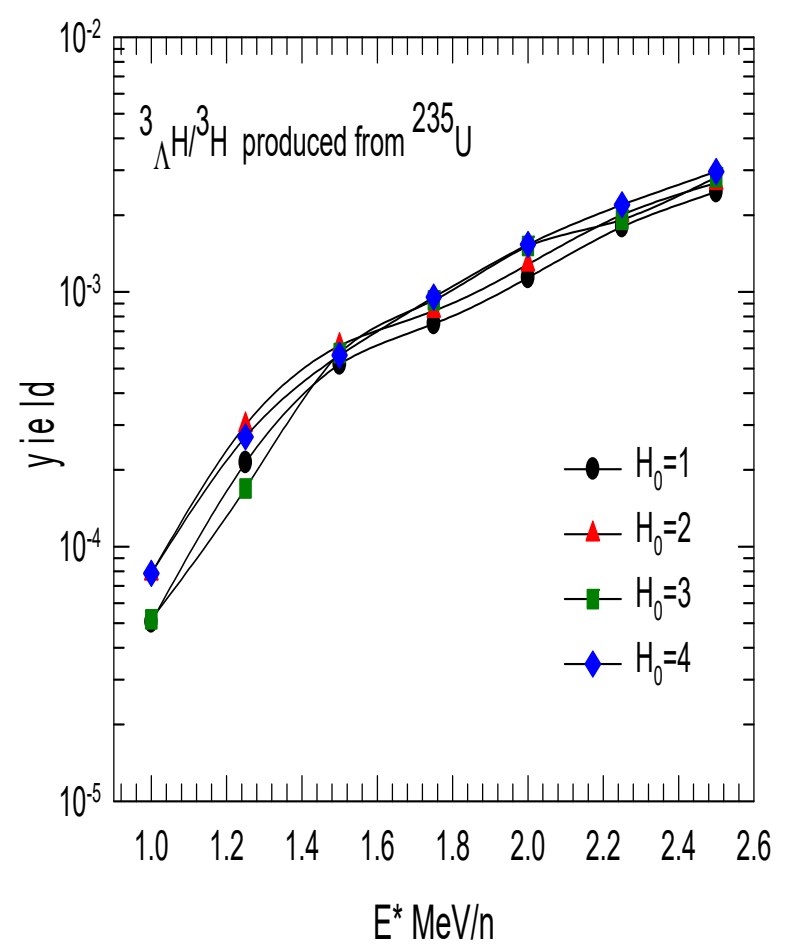

Figure 5. ${ }_{\Lambda}^{3} \mathrm{H} /{ }^{3} \mathrm{H}$ isotope ratios produced after decay of an excited hypernuclear system for $\mathrm{A}_{0}=$ $235, \mathrm{Z}_{0}=92$ with source $\Lambda$ hyperon number $\mathrm{H}_{0}=$ $1,2,3$ and 4 at different excitation energies. To increase the visibility, each data from bottom to top was increased by 20 percent.

In Fig. 2, we consider as source with $A_{0}=168, Z_{0}=67$, and $H_{0}=4$ to see how distributions change for low fissibility. One can clearly see only evaporation products of ${ }^{168} \mathrm{Ho}$ on the top panels, there are no fission events at excitation energies 0.25 and 0.5 $\mathrm{MeV} /$ nucleon. In the bottom panels, only few fission products can be found with very low probability. In our calculations, fission barriers of nuclei are modified for the cases including single and multi- $\Lambda$ nuclei as is done in Ref (Botvina et al., 2016).
Fig. 3 and 4 illustrate the relative yields over one million events of ${ }_{\Lambda}^{3} \mathrm{H}$ after emitted via evaporation after decay of excited hypernuclei, ${ }_{\Lambda}^{235} \mathrm{U},{ }_{\Lambda \Lambda}^{235} \mathrm{U},{ }_{3 \Lambda}^{235} \mathrm{U},{ }_{4 \Lambda}^{235} \mathrm{U}$, ${ }_{\Lambda}^{168} \mathrm{Ho}, \quad{ }_{\Lambda \Lambda}^{168} \mathrm{Ho}, \quad{ }_{3 \Lambda}^{168} \mathrm{Ho}, \quad$ and ${ }_{4 \Lambda}^{168} \mathrm{Ho}$ at excitation energies in between 1-2.6 $\mathrm{MeV} /$ nucleon. There is an ordering for the evolution of ${ }_{\Lambda}^{3} \mathrm{H}$ depending on $\Lambda$ number of sources and increasing probability with energy. As a further step, ${ }_{\Lambda}^{3} \mathrm{H} /{ }^{3} \mathrm{H}$ isotope ratios produced after decay of an excited hypernuclear system for ${ }_{\Lambda}^{235} \mathrm{U},{ }_{\Lambda \Lambda}^{235} \mathrm{U},{ }_{3 \Lambda}^{235} \mathrm{U}$, and ${ }_{4 \Lambda}^{235} \mathrm{U}$, sources are presented in Fig. 5. We believe that fission products and isotope ratios for hypernuclei can be measured in the future experiments at GSI and NICA.

\section{Acknowledgement}

Many helpful discussions with AS Botvina, R Ogul and A Kaya are gratefully acknowledged. This study is prepared from Master Thesis of S.N. Koyuncu at Graduate School of Natural Science of Selcuk University, supported by Scientific and Technological Research Council of Turkey (TUBITAK), under Project No. 118F111, and has been performed in the framework of COST Action CA15213 THOR.

\section{References}


Bondorf JP, Botvina AS, Iljinov AS, Mishustin IN, Sneppen K (1995). Statistical multifragmentation of nuclei. Phys Rep 257: 133-221.

Botvina AS, Mishustin IN, Begemann-Blaich M, Hubele J, Imme G, Iori I, Kreutz P, Kunde GJ, Kunze WD, Lindenstruth V, Lynen U, Moroni A, Müller WFJ, Ogilvie CA, Pochodzalla J, Raciti J, Rubehn Th, Sann H, Schüttauf A, Seidel W, Trautmann W, Wörner A (1995). Multifragmentation of spectators in relativistic heavy-ion reactions. Nucl Phys A 584(4): 737-756.

Botvina AS, Buyukcizmeci N, Ergun A, Ogul R, Bleicher M, Pochodzalla J (2016). Formation of hypernuclei in evaporation and fission processes. Phys Rev C 94: 054615.

Botvina AS, Iljinov AS, Mishustin IN, Bondorf J, Donangelo R, Sneppen K (1987). Statistical simulation of the break-up of highly excited nuclei. Nucl Phys A 475(4): 663-686.

Botvina AS, Pochodzalla J (2007). Production of hypernuclei in multifragmentation of nuclear spectator matter. Phys Rev C 76: 024909.

Buyukcizmeci N, Botvina AS, Ergun A, Ogul R, Bleicher M (2018). Statistical production and binding energy of hypernuclei. Phys Rev C 98: 064603.

Buyukcizmeci N, Botvina AS, Ogul R, Ergun A, Bleicher M (2019). Production of $\Lambda \Lambda$ hypernuclei and evaluation of their binding energies via the double yield ratio. Eur Phys $J$ A 55(2): 1 .

Buyukcizmeci N, Botvina AS, Pochodzalla J, Bleicher M (2013). Mechanisms for the production of hypernuclei beyond the neutron and proton drip lines. Phys Rev C 88: 014611.

Buyukcizmeci N, Ogul R, Botvina AS (2005). Isospin and symmetry energy effects on nuclear fragment production in liquid-gas-type phase transition region. Eur Phys $J$ A 25: 57.

Buyukcizmeci N, Ogul R, Botvina AS, Bleicher M (2020). On the survey of nuclei and hypernuclei in multifragmentation. Phys Scr 95: 075311.

Eren N, Buyukcizmeci N, Oğul R (2007). Mass distributions of nuclear disintegration from fission to evaporation. Phys Scr 76: 657.

Eren N, Buyukcizmeci N, Ogul R, Botvina AS (2013). Mass distribution in the disintegration of heavy nuclei. Eur Phys J A 49: 48.

Gal A, Hashimoto O, Pochodzalla J (Editors) (2012) Special issue on Progress in Strangeness Nuclear Physics. Nucl Phys A 881: 1-338.

Hashimoto O, Tamura H (2006). Spectroscopy of $\Lambda$ hypernuclei. Prog Part Nucl Phys 57: 564.

Imal H, Ergun A, Buyukcizmeci N, Ogul R, Botvina AS, Trautmann W (2015). Theoretical study of projectile fragmentation in the ${ }^{112} \mathrm{Sn}+{ }^{112} \mathrm{Sn}$ and ${ }^{124} \mathrm{Sn}+{ }^{124} \mathrm{Sn}$ reactions at 1 GeV/nucleon. Phys Rev C 91: 034605.

Karnaukhov VA, Oeschler H, Budzanowski A, Avdeyev SP, Botvina AS, Cherepanov EA, Karcz W, Kirakosyan VV, Rukoyatkin PA, Skwirczyńska I, Norbeck E (2008). Critical temperature for the nuclear liquid-gas phase transition (from multifragmentation and fission). Phys Atom Nuclei 71: 2067.

Kreutz P, Adioff JC, Begemann-Blaich M, Bouissou P, Hubele J, Imme G, Iori I, Kunde GJ, Leray S, Lindenstruth V, Liu Z, Lynen U, Meijer RJ, Milkau U, Moroni A, Müller WFJ, 
Ngô C, Ogilvie CA, Pochodzalla J, Raciti G, Rudolf G, Sann H, Schüttauf A, Seidel W, Stuttge L, Trautmann W, Tucholski A (1993). Charge correlations as a probe of nuclear disassembly. Nucl Phys A 556(4): 672-696.

Li BA, DeAngelis AR, Gross DHE (1993). Statistical model analysis of ALADIN multifragmentation data. Phys Lett B 303: 225.

Ogul R, Botvina AS, Atav U, Buyukcizmeci N, Mishustin IN, Adrich P, Aumann T, Bacri CO, Barczyk T, Bassini R, Bianchin S, Boiano C, Boudard A, Brzychczyk J, Chbihi A, Cibor J, Czech B, De Napoli M, Ducret JÉ, Emling H, Frankland JD, Hellström M, Henzlova D, Immè G, Iori I, Johansson H, Kezzar K, Lafriakh A, Le Fèvre A, Le Gentil E, Leifels Y, Lühning J, Łukasik J, Lynch WG, Lynen U, Majka Z, Mocko M, Müller WFJ, Mykulyak A, Orth H, Otte AN, Palit R, Pawłowski P, Pullia A, Raciti G, Rapisarda E, Sann H, Schwarz C, Sfienti C, Simon H, Sümmerer K, Trautmann W, Tsang MB, Verde G, Volant C, Wallace M, Weick H, Wiechula J, Wieloch A, Zwiegliński B (2011). Isospin-dependent multifragmentation of relativistic projectiles. Phys Rev C 83(2): 024608.

Pienkowski L, Kwiatkowski K, Lefort T, Hsi WC, Beaulieu L, Viola VE, Botvina A, Korteling RG, Laforest R, Martin E, Ramakrishnan E, Rowland D, Ruangma A, Winchester E, Yennello SJ, Back B, Breuer H, Gushue S, Remsberg LP (2002). Breakup time scale studied in the $8 \mathrm{GeV} / \mathrm{c} \pi-+197 \mathrm{Au}$ reaction. Phys Rev $C$ 65(6): 064606.

Schaffner J, Dover CB, Gal A, Greiner C, Stoecker H (1993). Strange hadronic matter. Phys Rev Lett 71: 1328.

Scharenberg RP, Srivastava BK, Albergo S, Bieser F, Brady FP, Caccia Z, Cebra DA, Chacon AD, Chance JL, Choi Y, Costa S, Elliott JB, Gilkes ML, Hauger JA, Hirsch AS, Hjort EL, Insolia A, Justice M, Keane D, Kintner JC, Lindenstruth V, Lisa MA, Matis HS, McMahan M, McParland C, Müller WFJ, Olson DL, Partlan MD, Porile NT, Potenza R, Rai G, Rasmussen J, Ritter HG, Romanski J, Romero JL, Russo GV, Sann H, Scott A, Shao Y, Symons TJM, Tincknell M, Tuvé C, Wang S, Warren P, Wieman HH, Wienold T, Wolf K (2001). Comparison of $1 \mathrm{AGeV197Au+C}$ data with thermodynamics: The nature of the phase transition in nuclear multifragmentation. Phys Rev C 64(5): 054602.

Viola VE, Lefort T, Beaulieu L, Kwiatkowski K, Wang G, De Souza R, Pienkowski L, Botvina A, Breuer H, Durand D, Korteling RG, Laforest R, Martin E, Ramakrishnan E, Rowland D, Ruangma A, Winchester E, Yennello SJ (2001). Signals for the transition from liguid to gas in hot nuclei. Nucl Phys A 681(1-4): 267-274.

Xi H, Odeh T, Bassini R, Begemann-Blaich M, Botvina AS, Fritz S, Gaff SJ, Groß C, Immé G, Iori I, Kleinevoß U, Kunde GJ, Kunze WD, Lynen U, Maddalena V, Mahi M, Möhlenkamp T, Moroni A, Müller WFJ, Nociforo C, Ocker B, Petruzzelli F, Pochodzalla J, Raciti G, Riccobene G, Romano FP, Rubehn TH, Saija A, Schnittker M, Schüttauf A, Schwarz C, Seidel W, Serfling V, Sfienti C, Trautmann W, Trzcinski A, Verde G, Wörner A, Zwieglinski B (1997). Breakup temperature of target spectators in ${ }^{197} \mathrm{Au}+{ }^{197} \mathrm{Au}$ collisions at $\mathrm{E} / \mathrm{A}=1000 \mathrm{MeV}$. Z Phys A 359: 397-406. 